\title{
МОРФО-БИОХИМИЧЕСКИЕ ПОКАЗАТЕЛИ И АКТИВНОСТЬ ПИЩЕВАРИТЕЛЬНЫХ ФЕРМЕНТОВ У КРЫС ЛИНИИ Wistar ПОД ВЛИЯНИЕМ РАЗЛИЧНЫХ ИСТОЧНИКОВ ХРОМА*
}

\author{
С.В. ЛЕБЕДЕВ 1,2 , И.А. ГАВРИШ ${ }^{1,2}$, И.3. ГУБАЙДУЛЛИНА ${ }^{1}$
}

Высокоэнергетические рационы, многокомпонентные кормовые смеси и добавки в составе современных рационов требуют особого внимания при оптимизации лимитируемых микроэлементов. Хром используется для коррекции углеводного, жирового и липидного обмена. Ввиду низкого содержания хрома в компонентах рациона роль этого элемента в формировании микроэкологического статуса организма малоизучена. От источника хрома зависит его биологическая доступность в организме. В представленной работе на модельном объекте (крысы линии Wistar) мы впервые сравнили биологическое действие различных форм хрома (пиколинат, наноформы и хлорид) в дозах 300 и 500 мкг/кг корма по комплексу показателей (усвояемость, гематологические показатели крови, активность пищеварительных ферментов, состав кишечной микрофлоры), установив высокую биодоступность и более выраженный положительный эффект пиколината и наночастиц (НЧ) хрома в отношении массы тела и гематологических показателей и неоднозначное влияние изученных форм на активность пищеварительных ферментов и микрофлору кишечника. Целью настоящей работы было исследование биологического действия хрома в различной форме и дозировке на крыс линии Wistar. Исследования проводили на 105 белых крысах-самцах массой 70-80 г в стандартных условиях вивария (ФНЦ биологических систем и агротехнологий РАН). Животных разделили на семь групп (по $n=15)$. Контрольная группа содержалась на об-

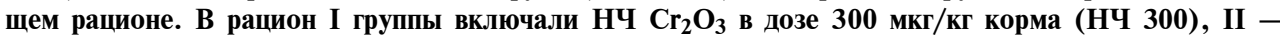
$\mathrm{CrCl}_{3}$ в дозе 300 мг/кг $\left(\mathrm{CrCl}_{3} 300\right)$, III - пиколинат хрома (CrPic) в дозе 300 мг/кг (CrPic 300), IV - НЧ $\mathrm{Cr}_{2} \mathrm{O}_{3}$ в дозе 500 мкг/кг корма (HЧ 500), $\mathrm{V}-\mathrm{CrCl}_{3}$ в дозе 500 мг/кг $\left(\mathrm{CrCl}_{3} \mathbf{5 0 0}\right)$, VI - CrPic в дозе 500 мг/кг (CrPic 500). Наночастицы вводили в комбикорм посредством ступенчатого смешивания. Введение СrPic и НЧ в дозе 500 мкг/кг на фоне одинакового расхода корма приводило к увеличению массы крыс на 22,6 и $22,2 \%$ (р $\leq 0,05)$. При воздействии НЧ $\mathrm{Cr}_{2} \mathrm{O}_{3}$ реакция лимфоцитов, моноцитов и гранулоцитов отсутствовала, в остальных случаях их количество превышало контрольные значения на 14-45 \%. В вариантах $\mathrm{HЧ} 300, \mathrm{CrCl}_{3} 300$ и $\mathrm{CrCl}_{3} 500$ синтез гемоглобина был адекватен стимуляции эритропоэза, но увеличение количества тромбоцитов приводило к сладжированию крови, повышению вязкости и затруднению перфузии через сосуды. Высокая усвояемость СrРіс и НЧ 500 (от 20,2 до 34,0 \%) сопровождалась проявлением гепато- и нефротоксичности с признаками окислительного стресса, снижением активности амилазы и липазы в плазме крови, что свидетельствует о депрессирующем влиянии высоких доз хрома на энтеропанкреатическую циркуляцию пищеварительных ферментов и нарушении обмена $\mathrm{Mg}$ и Fе в крови. Количество триглицеридов снижалось при максимальных дозах хрома в форме хлорида и пиколината, что подтверждает их участие в липидном обмене. Отсутствие токсичности при низких дозах (НЧ 300 и СrPic 300) наглядно демонстрировали показатели билирубина и креатинина. Активность амилазы в поджелудочной железе увеличивалась при НЧ 300. Включение СrPic в аналогичной дозировке стимулировало активность липазы и протеазы. $\mathrm{CrCl}_{3}$ и CrPic в дозировке 500 мкг/кг снижали активность липазы в 12-перстной кишке. Специфическое действие НЧ 500 на микроэкологический статус организма проявилось в снижении численности лактобактерий на 55,9 \%. Количество бифидобактерий было выше на 48,6 \% (p $\leq 0,05)$ в группе PicCr 500. Численность энтеробактерий в группе НЧ 300 оказалась ниже контроля на 34,8 \%, в то время как в остальных группах она увеличилась в $24,0-33,7$ раза (р $\leq 0,05)$. Таким образом, хром (CrPic 500, НЧ 300) не проявляет выраженного токсического эффекта на организм и оказывает стимулирующее действие на рост, развитие, активность пищеварительных энзимов и микроэкологический статус организма, что ставит эти формы в разряд перспективных источников хрома для коррекции обмена веществ и микрофлоры желудочно-кишечного тракта животных.

Ключевые слова: крысы, концентрация хрома, продуктивность, биохимические показатели крови, пищеварительные ферменты, кишечная микрофлора.

Хром (Cr) считается необходимым элементом для животных и человека, но понимание механизма его биологического действия остается не

\footnotetext{
* Работа выполняется при финансовой поддержке подпрограммы «Изучение механизмов адаптации системы пищеварения млекопитающих животных и птицы к рационам с различным ингредиентным составом кормов» (Постановление Президиума РАН № 132 от 05.07.2017) в рамках государственного задания № 0761-2018-0031).
} 
до конца изученным. Известно, что хром усиливает функцию инсулина, а также стимулирует скорость индуцированного инсулином набухания изолированных митохондрий (1), увеличивает респираторный фактор эпидидимальной жировой ткани (2), взаимодействует со щитовидной железой (3), играет важную роль в метаболизме белков, нуклеиновых кислот за счет значительного увеличения стимуляции включения аминокислот в белок печени in vitro (4). S. Okada c соавт. (5) установили, что непосредственное взаимодействие $\mathrm{Cr}$ с ДНК ведет к значительной стимуляции синтеза PHК in vitro, а также определили уникальный белок, содержащий 5-6 атомов $\mathrm{Cr}$, которому свойственны анаболические функции. Обнаружено новое Сr-связывающее вещество (6), которое потенцирует эффект инсулина при превращении глюкозы в липид и углекислый газ в изолированных адипоцитах (6).

Хотя хром существует в природе в состояниях окисления от $\mathrm{Cr}^{2-}$ до $\mathrm{Cr}^{6+}$, относительно инертные комплексы $\mathrm{Cr}^{3+}$ могут функционировать как структурные компоненты, которые связывают лиганды с надлежащей пространственной ориентацией, способствуя ферментативному катализу, а также поддерживают третичные структуры белков или нуклеиновых кислот (7). У кур включение дополнительного хрома в рацион улучшало показатели физиологического состояния и продуктивности при холодовом и тепловом стрессе $(8,9)$, а у свиней добавление 200 мкг пиколината хрома (CrPic) в рацион увеличивало скорость абсорбции азота (10).

В современном животноводстве наблюдается тенденция к замене традиционных минеральных источников микроэлементов на новые органо-минеральные или наноформы, что обусловлено их лучшей усвояемостью, биодоступностью и пролонгированным действием $(11,12)$. Показано, что метаболический ответ организма на хром зависит от его химической формы: органические источники имеют более высокую биодоступность (10$25 \%$ ), чем неорганические (3\%) (13). Уменьшение размера частиц хрома может увеличить скорость переваривания и абсорбции. T.F. Lien с соавт. (14) установили, что наночастицы CrPic значительно лучше усваивались по сравнению с обычным CrPic, что приводило к повышению содержания хрома в сыворотке крови у крыс. При включении наночастиц хрома в рацион свиней увеличивалась площадь длиннейшей мышцы и содержание хрома в тканях, уменьшалось жировое соотношение и толщина спинного жира $(15,16)$. В исследованиях на крысах наноразмерный хром значительно увеличил средний прирост массы тела, эффективность использования корма, соотношение жировых отложений, концентрацию инсулина в сыворотке крови и содержание хрома в органах (17).

Можно предположить, что изменение конверсии корма, мясной продуктивности и биохимических показателей у животных основано на механизмах участия хрома в пищеварении и обмене веществ через стимуляцию активности пищеварительных энзимов. Исследование альтернативных форм микроэлементов в рационе животных - необходимый инструмент для управления процессами пищеварения, формирования продуктивности и пищевой ценности животноводческой продукции.

В представленной работе на модельном объекте (крысы линии Wistar) мы впервые сравнили биологическое действие различных форм хрома (пиколинат, наноформы и хлорид) в дозах 300 и 500 мкг/кг корма по комплексу показателей (усвояемость, гематологические показатели крови, активность пищеварительных ферментов, состав кишечной микрофлоры), установив высокую биодоступность и более выраженное положительное влияние пиколината и наночастиц хрома на массу тела и гематологические показатели, а также неоднозначный эффект изученных форм в отношении 
активности пищеварительных ферментов и микрофлоры кишечника.

Целью настоящей работы было изучение биологического действия хрома в различной форме и дозировке на крыс линии Wistar.

Методика. Исследования проводили на 105 белых крысах-самцах линии Wistar массой 70-80 г в стандартных условиях вивария (ФНЦ биологических систем и агротехнологий РАН). Рацион животных (ГОСТ Р 5025892) соответствовал правилам лабораторной практики при проведении доклинических исследований в Российской Федерации (ГОСТ Р 51000.3-96 и Р 51000.4-96). Экспериментальную часть работы выполняли в соответствии с протоколами Женевской конвенции и принципами надлежащей лабораторной практики и «Тhe Guide for Care and Use of Laboratory Animals (National Academy Press Washington, D.C. 1996)». Крысы содержались в отдельных клетках со свободным доступом к воде и корму.

На основании результатов испытаний, проведенных ранее $(16,17)$, дозы хрома в наших экспериментах составили 300 и 500 мкг/кг корма. После подготовительного периода (7 сут) животных разделили на семь групп (по $n=15)$. Контрольная группа содержалась на общем рационе. В ра-

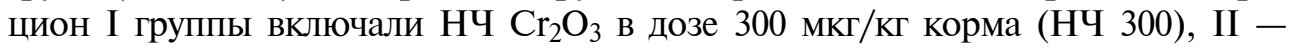
$\mathrm{CrCl}_{3}$ в дозе $300 \mathrm{мг/кг}\left(\mathrm{CrCl}_{3} 300\right)$, III - пиколинат хрома в дозе $300 \mathrm{мг/кг}$

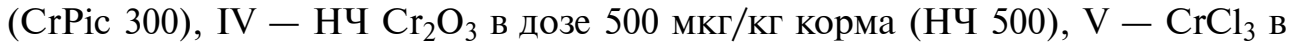
дозе 500 мг/кг $\left(\mathrm{CrCl}_{3} 500\right)$, VI - CrPic в дозе 500 мг/кг (CrPic 500). Наночастицы вводили в комбикорм при ступенчатом смешивании.

Ультрадисперсные частицы (УДЧ) хрома получали методом плазмохимического синтеза (ООО «Платина», г. Москва; $\mathrm{d}=91 \mathrm{нм}$, удельная

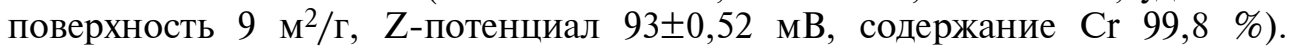
Препараты наночастиц диспергировали в физиологическом растворе с помощью УЗДН-2Т («НПП Академприбор», Россия; 35 кГц, 300 Вт, 10 мкА, 30 мин). Использовали также неорганическую форму $\mathrm{Cr}$ в форме хлорида хрома $\mathrm{CrCl}_{3} \cdot 6 \mathrm{H}_{2} \mathrm{O}$ ч.д.а $(19,5 \% \mathrm{Cr})$ (АО «Реахим», Россия) и пиколинат хрома (содержит $10 \%$ органического хрома; ЗАО «Эвалар», Россия).

В начале и конце эксперимента (21-е сут) учитывали ростовые показатели и расход корма. Кровь отбирали из хвостовой вены в вакуумные пробирки с добавлением антикоагулянта, для биохимических показателей в вакуумные пробирки с активатором свертывания (тромбин). Морфологический анализ крови проводили на автоматическом гематологическом анализаторе URIT-2900 Vet Plus («URIT Medical Electronic Group Co., Ltd», Китай), биохимический анализ сыворотки крови - на автоматическом анализаторе CS-T240 («DIRUI Industrial Co., Ltd», Китай) с коммерческими наборами для ветеринарии (ЗАО «ДИАКОН-ДС», Россия).

После декапитации крыс на 21-е сут под нембуталовым наркозом (5 особей из каждой группы) отбирали биосубстраты для анализа. Концентрацию хрома определяли в начале и конце эксперимента в измельченных образцах биоматериала (все ткани и системы организма), корма и фекалий с последующим озолением в микроволновой системе разложения Multiwave 3000 («Anton Paar», Австрия). Элементный состав исследовали методами атомно-эмиссионной спектрометрии (Optima 2000 V, «Perkin Elmer», США) и масс-спектрометрии (Elan 9000, «Perkin Elmer», США).

Перевариваемость хрома оценивали на основании общего сбора биосубстратов (кал, моча) в период проведения балансового опыта (5 сут) в индивидуальных метаболических клетках (http://цтт-ягпу.pф/dxl-d). Усвояемость $\mathrm{Cr}(\mathrm{У}, \%)$ рассчитывали по формуле: $\mathrm{У}=\{[($ индивидуальное потребление корма $\times$ \% Cr) - (количество фекалий и мочи за период 5 сут в граммах $\times \% \mathrm{Cr})] \times$ (индивидуальное потребление корма для крыс $\times \%$ 
$\mathrm{Cr})\} \times 100$.

Для оценки состояния ферментативной системы животным после убоя рассекали брюшную стенку, извлекали 12-перстную кишку и поджелудочную железу. Для подготовки проб тканей исследуемых органов навески (1 г) растирали в охлажденном растворе Рингера (4 мл), гомогенат центрифугировали при 3000 об/мин в течение 10 мин (СМ-12, «Фабрика НВгрупп», Россия). Амилазную активность определяли по методу H. Coles (18), липазную - по J.H. Boutwell (19), протеазную - с использованием методики Ц.Ж. Батоева (20). Активность исследованных ферментов выражали в условных единицах (усл. ед., разность показаний пробы с субстратом и холостой пробы в расчете на 1 г влажной навески ткани слизистой кишечника за 1 мин).

Образцы содержимого кишечника собирали в стерильные пробирки Эппендорф. Для комплексного изучения микрофлоры по 0,1 мл каждого из 10-кратных разведений высевали на питательные среды по стандартной методике (21). Использовали Эндо-агар, мясо-пептонный агар (МПА), желточно-солевой агар (ЖСА) (ООО «НИЦФ», Россия), Rogosa agar, Bifidobacterium Agar, BCA («HiMedia Laboratories Pvt. Ltd», Индия). Окончательный результат количественного содержания бактерий в грамме фекалий выражали как KOE/г.

Все эксперименты проводили в 3-кратной повторности. Статистическая обработка полученных результатов включала расчет среднего значения $(M)$ и стандартных ошибок среднего $( \pm \mathrm{SEM})$. Достоверность различий сравниваемых показателей определяли по $t$-критерию Стьюдента. Статистически значимыми считали различия при $\mathrm{p}<0,05$. Статистический анализ выполняли с использованием ANOVA (программный пакет Statistica 10.0, «StatSoftInc.», США) и Microsoft Excel.

Результаты. На фоне практически одинакового расхода корма за

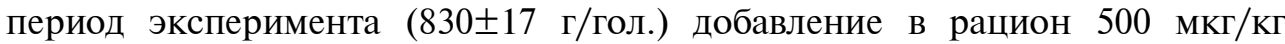
CrPic и НЧ 500 сопровождалось увеличением массы крыс на 22,6 и 22,2 \% $(\mathrm{p} \leq 0,05)$ и снижением соотношения количества брюшного жира к массе тела. Масса печени и почек существенно не отличалась от контрольных значений. Аналогично в исследованиях T.F. Lien с coaвт. (14) дополнительное включение в рацион $\mathrm{Cr}(0,2$ мг) увеличивало среднесуточный прирост массы без повышения расхода корма и нивелировало отложения жира. О сходном влиянии органических и наноформ хрома по сравнению с его минеральной формой сообщалось ранее (13).

Был установлен положительный баланс в накоплении хрома при использовании в рационе CrPic в дозах 300 и 500 мкг/кг, что сравнимо с результатами исследований M.Q. Wang с соавт. (15). Биодоступность НЧ $\mathrm{Cr}$ достигала наибольшего положительного баланса при дозе 500 мкг/кг и была выше контроля на 81,6 \%. В остальных группах усвояемость хрома находилась в диапазоне 4,3-7,5 \% и была наименьшей при использовании $\mathrm{CrCl}_{3}$ (табл. 1).

Ранее в исследованиях M.Q. Wang с соавт. (15) была описана способность наночастиц хрома стимулировать ростовые показатели, увеличивая при этом отложение металла в мышцах, сердце, печени и почках. Это происходит за счет лучшего поглощения наноформы $\mathrm{Cr}$ в кишечнике и высокой проникающей способности частиц $\mathrm{Cr}$ через кровеносные капилляры (23). Всосавшийся хром связывается в основном с трансферрином, распределяется по тканям в зависимости от химического состояния, в котором элемент поступил в организм (24), выводится с мочой и фекалиями в форме ацетатных и цитратных комплексов в течении 4 сут в количестве 
1. Морфометрические показатели и усвояемость различных форм хрома у крыс линии Wistar $(M \pm S E M$, опыт в условиях вивария)

\begin{tabular}{|c|c|c|c|c|c|c|c|}
\hline \multirow{2}{*}{ Показатель } & \multicolumn{7}{|c|}{ Группа } \\
\hline & контрольная & I & II & III & IV & $\mathrm{V}$ & VI \\
\hline Начальная масса тела, г & $69,30 \pm 2,95$ & $114,20 \pm 2,80$ & $75,50 \pm 2,88$ & $87,90 \pm 1,19$ & $101,80 \pm 7,63$ & $81,10 \pm 3,13$ & $100,30 \pm 5,50$ \\
\hline Живая масса в конце опыта, г & $118,60 \pm 3,50$ & $149,30 \pm 0,10$ & $131,20 \pm 9,86$ & $146,70 \pm 7,01$ & $152,30 \pm 6,30^{*}$ & $123,30 \pm 4,17$ & $151,50 \pm 6,50^{*}$ \\
\hline Масса печени, г & $5,55 \pm 0,49$ & $5,03 \pm 0,43$ & $6,88 \pm 0,43$ & $7,90 \pm 0,45^{*}$ & $6,50 \pm 0,32$ & $6,23 \pm 0,67$ & $6,70 \pm 0,45$ \\
\hline Масса почек, г & $1,20 \pm 0,08$ & $1,13 \pm 0,06$ & $1,15 \pm 0,16$ & $1,43 \pm 0,27$ & $1,23 \pm 0,19$ & $1,43 \pm 0,23$ & $1,53 \pm 0,22^{*}$ \\
\hline Внутренний жир, & $1,33 \pm 0,21$ & $1,21 \pm 0,10$ & $1,80 \pm 0,37^{*}$ & $1,63 \pm 0,21$ & $1,25 \pm 0,09$ & $1,37 \pm 0,79$ & $2,10 \pm 0,30^{*}$ \\
\hline г/отношение к массе тела & 2 & 1,06 & 1,38 & 1,12 & 0,82 & 1,12 & 1,39 \\
\hline Прирост, г & $49,30 \pm 1,10$ & $35,10 \pm 0,90^{*}$ & $55,70 \pm 1,20$ & $58,80 \pm 2,30^{*}$ & $50,50 \pm 1,35$ & $42,20 \pm 0,95$ & $51,20 \pm 1,32$ \\
\hline Содержание в рационе $\mathrm{Cr}$, мг/кг & 0,13 & 0,43 & 0,43 & 0,43 & 0,63 & 0,63 & 0,63 \\
\hline Содержание Cr в кале, мг/кг & $0,97 \pm 0,01$ & $3,18 \pm 0,12 * * *$ & $3,27 \pm 0,18^{* * *}$ & $2,75 \pm 0,05^{* * *}$ & $3,30 \pm 0,13^{* * *}$ & $4,83 \pm 0,24^{* * *}$ & $4,02 \pm 0,74 * * *$ \\
\hline Содержание Cr в теле, мг/кг & $0,18 \pm 0,05$ & $0,05 \pm 0,00^{*}$ & $0,05 \pm 0,00^{*}$ & $0,06 \pm 0,00$ & $0,21 \pm 0,04$ & $0,06 \pm 0,00^{*}$ & $0,09 \pm 0,00^{*}$ \\
\hline Усвояемость Сr, \% & $6,7 \pm 0,3$ & $7,6 \pm 0,4^{*}$ & $4,9 \pm 0,6^{*}$ & $20,2 \pm 1,1^{* *}$ & $34,5 \pm 1,3^{*}$ & $4,3 \pm 0,9^{*}$ & $20,2 \pm 1,6$ \\
\hline
\end{tabular}

2. Морфологические показатели крови у крыс линии Wistar на 21-е сут после введения в рацион хрома в различных формах и дозировках ( $M \pm \mathrm{SEM}$, опыт в условиях вивария)

\begin{tabular}{|c|c|c|c|c|c|c|c|}
\hline \multirow{2}{*}{ Показатель } & \multicolumn{7}{|c|}{ Группа } \\
\hline & контрольная & I & II & III & IV & $\mathrm{V}$ & VI \\
\hline Лейкоциты, × $10^{9} /$ л & $7,50 \pm 3,50$ & $11,00 \pm 1,60^{*}$ & $10,70 \pm 1,10$ & $12,20 \pm 2,60^{*}$ & $7,10 \pm 1,70$ & $8,80 \pm 2,10$ & $9,00 \pm 2,10$ \\
\hline Лимфоциты, $\times 10^{9} / л$ & $3,80 \pm 1,80$ & $6,50 \pm 2,10^{*}$ & $5,80 \pm 0,70^{*}$ & $5,10 \pm 1,40^{*}$ & $3,80 \pm 1,10$ & $4,60 \pm 0,90^{*}$ & $5,20 \pm 1,20^{*}$ \\
\hline Моноциты, ×109/л & $1,60 \pm 0,80$ & $2,10 \pm 0,80$ & $1,70 \pm 0,10$ & $2,30 \pm 0,90$ & $1,60 \pm 0,80$ & $1,70 \pm 0,01$ & $1,70 \pm 0,30$ \\
\hline Гранулоциты, $\times 10^{9} / л$ & $2,10 \pm 0,78$ & $2,40 \pm 0,90$ & $3,00 \pm 0,30$ & $4,80 \pm 1,10^{*}$ & $1,70 \pm 1,07$ & $2,50 \pm 0,08$ & $2,40 \pm 0,20$ \\
\hline Эритроциты, $\times 10^{12} /$ л & $4,69 \pm 0,63$ & $5,79 \pm 1,10$ & $5,70 \pm 0,70$ & $5,64 \pm 1,80$ & $5,67 \pm 1,70$ & $5,21 \pm 0,80$ & $5,36 \pm 1,10$ \\
\hline Гемоглобин, г/л & $103,00 \pm 15,60$ & $128,00 \pm 22,10^{*}$ & $125,00 \pm 3,60^{*}$ & $125,00 \pm 23,10^{*}$ & $119,00 \pm 12,50$ & $115,00 \pm 12,60$ & $119,00 \pm 23,60$ \\
\hline Гематокрит, \% & $26,40 \pm 7,80$ & $31,40 \pm 11,20$ & $30,70 \pm 11,50$ & $32,00 \pm 9,90^{*}$ & $28,00 \pm 9,68$ & $28,10 \pm 3,60$ & $29,10 \pm 2,40$ \\
\hline Тромбоциты, $\times 10^{9} / л$ & $120,00 \pm 25,30$ & $233,00 \pm 35,20^{*}$ & $237,00 \pm 23,60^{*}$ & $169,00 \pm 25,30$ & $110,00 \pm 15,60$ & $204,00 \pm 9,80^{*}$ & $186,00 \pm 12,50$ \\
\hline
\end{tabular}


3. Биохимические показатели сыворотки крови у крыс линии Wistar на 21-е сут после введения в рацион хрома в различных формах и дозировках ( $M \pm \mathrm{SEM}$, опыт в условиях вивария)

\begin{tabular}{|c|c|c|c|c|c|c|c|}
\hline \multirow{2}{*}{ Показатель } & \multicolumn{7}{|c|}{ Группа } \\
\hline & контрольная & I & II & III & IV & V & VI \\
\hline Глюкоза, ммоль/л & $3,11 \pm 1,40$ & $1,99 \pm 0,90$ & $2,44 \pm 1,10$ & $3,78 \pm 1,80$ & $7,00 \pm 2,10^{*}$ & $7,74 \pm 2,10^{*}$ & $2,32 \pm 1,60$ \\
\hline Общий белок, г/л & $63,60 \pm 9,80$ & $68,30 \pm 10,30$ & $57,90 \pm 16,30$ & $63,30 \pm 9,70$ & $64,90 \pm 11,60$ & $62,50 \pm 12,10$ & $61,60 \pm 9,90$ \\
\hline Билирубин общий, мкмоль/л & $8,90 \pm 0,40$ & $8,30 \pm 2,10$ & $6,80 \pm 1,10^{*}$ & $7,10 \pm 0,90$ & $11,60 \pm 1,50$ & $10,90 \pm 2,10$ & $9,60 \pm 1,90$ \\
\hline Холестерин, ммоль/л & $1,85 \pm 1,90$ & $1,59 \pm 0,68$ & $1,48 \pm 0,78$ & $2,27 \pm 0,68$ & $1,85 \pm 1,30$ & $1,80 \pm 0,80$ & $1,45 \pm 0,35$ \\
\hline Триглицериды, ммоль/л & $9,63 \pm 1,80$ & $10,80 \pm 3,60$ & $8,61 \pm 2,80$ & $7,69 \pm 2,10$ & $6,84 \pm 2,10$ & $5,88 \pm 1,20^{*}$ & $5,69 \pm 1,60^{*}$ \\
\hline Мочевина, ммоль/л & $7,20 \pm 1,10$ & $7,60 \pm 2,40$ & $5,90 \pm 2,10$ & $5,30 \pm 1,90$ & $4,00 \pm 1,40^{*}$ & $6,40 \pm 1,30$ & $6,10 \pm 1,80$ \\
\hline Креатинин, мкмоль/л & $29,70 \pm 8,90$ & $27,60 \pm 11,30$ & $33,90 \pm 9,60$ & $30,80 \pm 11,10$ & $19,70 \pm 4,30$ & $33,90 \pm 2,10$ & $36,10 \pm 3,10$ \\
\hline Кальций, ммоль/л & $1,80 \pm 0,40$ & $2,00 \pm 0,11$ & $1,88 \pm 0,01$ & $2,27 \pm 0,20$ & $1,98 \pm 0,60$ & $1,94 \pm 0,27$ & $2,10 \pm 0,21$ \\
\hline Железо, мкмоль/л & $41,00 \pm 7,60$ & $41,10 \pm 11,4$ & $27,30 \pm 8,70^{*}$ & $29,70 \pm 7,70^{*}$ & $49,50 \pm 8,10$ & $35,80 \pm 4,10$ & $32,40 \pm 5,60$ \\
\hline Амилаза, Ед/л & $1266,00 \pm 42,30$ & $1112,90 \pm 45,30$ & $1130,60 \pm 39,60$ & $1578,00 \pm 23,60$ & $1414,00 \pm 19,60$ & $643,80 \pm 122,30^{*}$ & $648,00 \pm 214,30^{*}$ \\
\hline Липаза, Ед/л & $2,40 \pm 0,70$ & $4,80 \pm 2,40$ & $0,80 \pm 1,10^{* *}$ & $2,10 \pm 1,10$ & $3,10 \pm 0,90$ & $1,10 \pm 0,01^{*}$ & $1,60 \pm 0,03^{*}$ \\
\hline Магний, ммоль/л & $0,90 \pm 0,04$ & $0,68 \pm 0,04$ & $0,78 \pm 0,01$ & $0,45 \pm 0,01$ & $1,17 \pm 0,07$ & $0,63 \pm 0,01$ & $0,52 \pm 0,02$ \\
\hline Фосфор, ммоль/л & $3,65 \pm 0,80$ & $3,82 \pm 1,40$ & $3,59 \pm 1,40$ & $4,04 \pm 2,10$ & $1,87 \pm 1,30^{* *}$ & $5,18 \pm 1,20^{*}$ & $3,86 \pm 1,60$ \\
\hline
\end{tabular}

4. Активность (Ед/мл) пищеварительных ферментов в поджелудочной железе и двенадцатиперстной кишке у крыс линии Wistar на 21-е сут после введения в рацион хрома в различных формах и дозировках (M $\pm \mathrm{SEM}$, опыт в условиях вивария)

\begin{tabular}{|c|c|c|c|c|c|c|}
\hline \multirow{2}{*}{ Группа } & \multicolumn{3}{|c|}{ Двенадцатиперстная кишка } & \multicolumn{3}{|c|}{ Поджелудочная железа } \\
\hline & амилаза & протеаза & липаза & амилаза & протеаза & липаза \\
\hline Контрольная & $81,8 \pm 6,7$ & $2,0 \pm 0,4$ & $0,9 \pm 0,2$ & $31,5 \pm 0,5$ & $2,0 \pm 0,2$ & $4,1 \pm 0,4$ \\
\hline I & $90,7 \pm 13,2$ & $4,6 \pm 1,2$ & $0,3 \pm 0,1$ & $88,8 \pm 4,7^{*}$ & $1,9 \pm 0,1$ & $4,4 \pm 0,7$ \\
\hline II & $58,4 \pm 10,8$ & $3,6 \pm 0,2$ & $2,3 \pm 0,6$ & $32,8 \pm 10,2$ & $2,6 \pm 0,1$ & $4,3 \pm 0,2$ \\
\hline III & $37,4 \pm 5,1^{*}$ & $3,1 \pm 0,2$ & $2,7 \pm 0,2^{*}$ & $5,8 \pm 2,3^{*}$ & $4,1 \pm 0,4^{*}$ & $13,7 \pm 0,5^{*}$ \\
\hline IV & $80,7 \pm 9,8$ & $2,5 \pm 0,3$ & $1,3 \pm 0,3$ & $32,3 \pm 1,1$ & $2,5 \pm 0,4$ & $5,9 \pm 0,7$ \\
\hline V & $72,8 \pm 13,3$ & $2,2 \pm 0,2$ & $2,8 \pm 0,4^{*}$ & $54,4 \pm 7,8$ & $2,6 \pm 0,4$ & $3,7 \pm 0,6$ \\
\hline VI & $85,7 \pm 7,5$ & $2,9 \pm 0,7$ & $4,1 \pm 0,5^{*}$ & $55,4 \pm 9,4$ & $1,7 \pm 0,1$ & $5,2 \pm 0,3$ \\
\hline
\end{tabular}


60-90\% от поступившего хрома (25).

Чтобы избежать искажения в интерпретации данных при оценке действия различных форм хрома на организм, особенно в концентрации, превышающей биотическую, необходимо использовать маркеры. Они должны исключать скрытые токсические эффекты, которые связаны с нарушением обмена веществ и выражаются в накоплении жира, изменении гематологических и биохимических параметров крови (27) (табл. 2).

В нашем эксперименте особенностью действия дозы НЧ 500 было отсутствие реакции лимфоцитов, моноцитов и гранулоцитов, в то время как при дозе НЧ 300 эти показатели превышали контрольные значения на $14-45 \%$ ( $\leq 50,05)$. Обнаруженные эффекты хрома в отношении группы форменных элементов сходны с таковыми при внесении НЧ меди и железа (28). Добавление хрома в рацион крыс стимулировало эритропоэз, наибольший эффект достигался при концентрации CrPic 300: показатель гематокрита у животных в III группе был на $17,5 \%$ (p $\leq 0,05)$ больше, чем в контроле. Синтез гемоглобина соответствовал стимуляции эритропоэза, но увеличение количества тромбоцитов приводило к сладжированию крови, повышению вязкости и затруднению перфузии через сосуды. Эта симптоматика была характерна для $\mathrm{HЧ} 300, \mathrm{CrCl}_{3} 300$ и $\mathrm{CrCl}_{3} 500$ (разница с контролем от 70 до $90 \%, \mathrm{p} \leq 0,05)$. Причиной такого эффекта могла быть тромбогенность наночастиц, а в случае с $\mathrm{CrCl}_{3}-$ проявление токсических свойств этого соединения.

Два аспекта биосовместимости наноматериалов - тромбогенность и гемолитическая активность требуют особого внимания, поскольку после проникновения через барьерные структуры организма наночастицы оказываются в лимфе и кровотоке, что предполагает их контакт как с макромолекулами плазмы крови и лимфы, так и с форменными элементами. Известно, что частицы с отрицательным зарядом поверхности могут запускать образование тромба посредством контактной активации каскада свертывания крови, приводящей к образованию фибрина, то есть они активируют внешний путь свертывания крови.

Мы установили гипер- и гипогликемический эффект влияния хрома в различных формах и дозировках на организм крыс (табл. 3). Поскольку 65-70 \% циркулирующей в крови глюкозы утилизируется центральной нервной системой, это предопределяет опасность гипогликемических состояний, существенно изменяющих метаболизм мозга, что в конечном итоге приводит к гибели нейронов и нарушению его функции (29). Так, в IV и V опытных группах было отмечено достоверное увеличение содержания глюкозы в 2,49 и 2,25 раза $(\mathrm{p} \leq 0,05)$. Концентрация общего белка между группами достоверно не различалась. Максимальное снижение содержания креатинина наблюдали в крови у крыс из IV группы (на 33,7 \%), что, наряду со снижением содержанием мочевины на $44,4 \%$ ( $\leq 5,05)$, было одним из критериев нарушений в работе выделительного аппарата (17).

Количество триглицеридов как истинных жиров снижалось при максимальных дозах хрома в форме хлорида и пиколината, что свидетельствует о влиянии хрома на липидный обмен, о расщеплении избыточного жира в организме и снижении коэффициента соотношения количества жира к массе с 2,00 (контроль) до 0,82 (НЧ 500). Влияние хрома на липидный обмен также опосредуется его регулирующим действием на функционирование инсулина. 
Активность панкреатических ферментов амилазы и липазы в плазме крови снижалась с увеличением содержания $\mathrm{CrCl}_{3}$ и $\mathrm{CrPic}$ в корме, что указывает на депрессирующее воздействие используемых форм хрома на энтеропанкреатическую циркуляцию пищеварительных ферментов. При внесении НЧ 500 снижалось содержание фосфора на 48,8 \% (p $\leq 0,05)$. Интересны данные, касающиеся содержания в сыворотке крови железа. Если при низкой концентрации хром и железо преимущественно занимают различные сайты связывания $(30,31)$, то при более высоком содержании они конкурируют за них, что проявилось в снижении метаболизма железа в опытных группах, получавших рацион с хлоридом и пиколинатом хрома. Анализ реакции аминотрасфераз (рис.) как индикатора наличия повреждений в клетках установил снижение активности АсАТ на 42,7 \% при дозе НЧ 500 (р $\leq 0,01)$ и увеличение при НЧ 300, CrPic 300, CrPic 500 в $1,97(\mathrm{p} \leq 0,001) ; 3,75(\mathrm{p} \leq 0,001) ; 2,14$ раза $(\mathrm{p} \leq 0,01)$ в сравнении с контролем на фоне стабильно высокого содержания билирубина. Это объясняется массированным выходом ферментов в кровяное русло при разрушении клеток, вызванном началом окислительного стресса и различными патологическими процессами. Достоверное снижение активности АлАТ на 10,7\% (p $\leq 0,05)$ при воздействии НЧ 500 может быть косвенным признаком нарушения клубочковой фильтрации, что подтверждается снижением содержания креатинина на $33,7 \%$ (p $\leq 0,05)$ относительно контроля (рис., А).

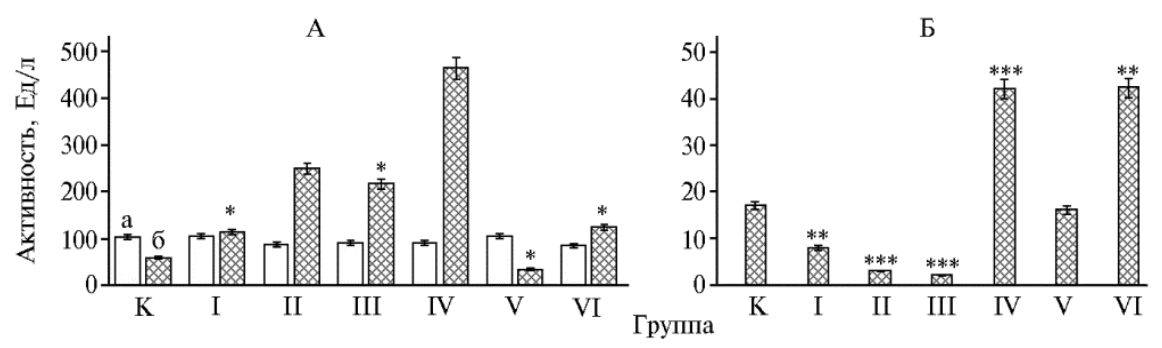

Активность аминотрансфераз (А) и $\gamma$-глутамилтрансферазы (Б) в сыворотке крови у крыс линии Wistar на 21-е сут после введения в рацион ультрадисперсных частиц хрома в разных формах и дозировках: а - аланинаминотрансфераза, б - аспартатаминотрансфераза; K - контроль, I НЧ $\mathrm{Cr}_{2} \mathrm{O}_{3}\left(300 \mathrm{мкг} / \mathrm{кг} \mathrm{корма),} \mathrm{II}-\mathrm{CrCl}_{3}(300 \mathrm{мг} / \mathrm{кг})\right.$, III $-\mathrm{CrPic}(300 \mathrm{мг} / \mathrm{Kг})$, IV - НЧ $\mathrm{Cr}_{2} \mathrm{O}_{3}(500 \mathrm{мкг} / \mathrm{кг}), \mathrm{V}-\mathrm{CrCl}_{3}(500$ мг/кг), VI $-\mathrm{CrPic}(500$ мг/кг) $(M \pm \mathrm{SEM}, n=15$, опыт в условиях вивария).

*, ** и *** Различия с контролем статистически значимы соответственно при $\mathrm{p} \leq 0,05$, $\mathrm{p} \leq 0,01$ и $\mathrm{p} \leq 0,001$.

Анализ активности $\gamma$-глутамилтрансферазы $(\gamma$-ГТ) в сыворотке крови выявил достоверное увеличение при введении в рацион НЧ 500 и CrPic 500, что могло быть обусловлено гибелью клеток, застоем внутри протоков или токсическим воздействием на фоне интоксикации (32). Введение НЧ $\mathrm{Cr}_{2} \mathrm{O}_{3}, \mathrm{CrCl}_{3}$ и $\mathrm{CrPic}$ в дозе 300 мг/кг приводило к снижению этого показателя. НЧ $\mathrm{Cr}_{2} \mathrm{O}_{3}$ в дозе 500 мг/кг оказали наибольшее влияние на гематологические показатели. Неоднозначное проявление активности ферментов переаминирования, с одной стороны, может свидетельствовать о разрушении мембран клеток, с другой - о слабой индукции микросомального окисления под влиянием НЧ переменной валентности (33). Остальные формы хрома в использованных дозировках не привели к критическим изменениям в системе гемостаза.

Способность хрома быстро проникать в отделы кишечника (через 1 ч после кормления) и образовывать в нем стабильные трудно абсорбируе- 
мые гидраты предполагает его участие в выработке пищеварительных ферментов (34). В нашем исследовании наблюдалось стимулирование активности амилазы в поджелудочной железе при внесении НЧ 300 и уменьшении этого показателя в варианте с использованием CrPic 300. При этом CrPic оказывал стимулирующее воздействие на активность липазы и протеазы. В 12-перстной кишке снижение активности амилазы на 54,3\% (p $\leq 0,05)$ и увеличение активности липазы на 67,7 \% (p $\leq 0,05)$ было характерно для $\mathrm{CrPic} 300$. Добавление в рацион крыс НЧ $\mathrm{CrCl} 3$ и $\mathrm{CrPic}$ в дозировке 500 мкг/кг стимулировало активность липазы (табл. 4).

Несмотря на отсутствие в мировой научной литературе данных, объясняющих механизм действия НЧ хрома на пищеварительные ферменты, перспективной представляется возможность модулировать их активность за счет индукции. Адсорбция биологических макромолекул на поверхности наночастицы может изменять их пространственную структуру и, соответственно, некоторые функциональные свойства. Так, фермент $\alpha$-химотрипсин, адсорбированный на однослойных углеродных нанотрубках, теряет 99 \% активности из-за нарушения вторичной структуры (35). При адсорбции белков на наночастицах большего размера, благодаря образованию дополнительных контактов, наблюдаются выраженные изменения структуры и функции белков (36).

Учитывая разнополярность действия хрома на активность пищеварительных ферментов, необходимо подчеркнуть, что наночастицы и пиколинат обладают сходным действием за счет возможного непосредственного контакта с активным центром фермента (37).

5. Численность микроорганизмов $\left(\times 10^{6} \mathrm{KOE} / \Gamma\right)$ в толстом кишечнике у крыс линии Wistar на 21-е сут после введения в рацион хрома в различных формах и дозировках ( $M \pm \mathrm{SEM}$, опыт в условиях вивария)

\begin{tabular}{|c|c|c|c|c|c|c|c|}
\hline \multirow{2}{*}{ Микроорганизмы } & \multicolumn{7}{|c|}{ Группы } \\
\hline & контрольная & $\mathrm{I}$ & II & III & IV & $\mathrm{V}$ & VI \\
\hline Лактобактерии & $14,3 \pm 2,1$ & $9,3 \pm 1$ & $10 \pm 1,1$ & $12,6 \pm 2,1$ & $6,3 \pm 0,8^{*}$ & $8,0 \pm 1,1$ & $8,6 \pm 0,4$ \\
\hline Бифидобактерии & $14,9 \pm 4,1$ & $11,7 \pm 0,9$ & $12,3 \pm 1,5$ & $13,1 \pm 0,9$ & $6,5 \pm 0,4$ & $22,0 \pm 2,2$ & $29,0 \pm 2.5^{*}$ \\
\hline Энтеробактерии & $0,8 \pm 0,1$ & $0,5 \pm 0,1^{*}$ & $25,0 \pm 2,3^{* *}$ & $29,0 \pm 3,1^{* *}$ & $23,0 \pm 3,7^{* *}$ & $20,6 \pm 2,4^{*}$ & $26,0 \pm 2,9 * *$ \\
\hline $\begin{array}{l}\text { П р и м е ч а н и е. OI } \\
* \text { и ** Различия с кою }\end{array}$ & $\begin{array}{l}\text { ание групп см. } \\
\text { олем статистич }\end{array}$ & $\begin{array}{l}\text { азделе «М } \\
\text { и значимь }\end{array}$ & $\begin{array}{l}\text { етодика». } \\
\text { соответств }\end{array}$ & IHO П & & $\leq 0,01$. & \\
\hline
\end{tabular}

Численность лактобактерий в IV группе была на 55,9 \% (p $\leq 0,05)$ ниже, чем в контроле, в остальных - достоверно не изменялась. Количество бифидобактерий в VI группе оказалось на 48,6 \% выше контрольного $(\mathrm{p} \leq 0,01)$. Численность энтеробактерий в группе НЧ 300 была ниже, чем в контроле, на 34,8 \% (p $\leq 0,05)$, в то время как в остальных группах их количество увеличилось в 24,0-33,7 раза (табл. 5).

Таким образом, хром в форме наночастиц и пиколината в дозе до 300 мкг/кг может быть использован в качестве бактериостатического агента для коррекции содержания бифидобактерий в кишечнике. Содержание билирубина и креатинина, увеличение активности амилазы в поджелудочной железе, липазы и протеазы в 12-перстной кишке наглядно продемонстрировали отсутствие токсичности НЧ 300 и CrPic 300 для крыс линии Wistar. Применение хрома в дозе 500 мкг/кг, независимо от формы элемента, сопровождалось проявлением гепато- и нефротоксичности с признаками окислительного стресса. Высокая усвояемость СrPic и НЧ 500 (от 20,2 до 34,0 \%) оказывала депрессирующее воздействие на энергетический обмен и энтеропанкреатическую циркуляцию пищеварительных ферментов, снижалось содержание триглицеридов и коэффициент соотношения между количеством жира и массы тела. Депрессия липидного обмена под- 
тверждалась снижением активности амилазы в 12-перстной кишке. В целом перспективность использования наноразмерных подкормок обусловлена преобладанием поверхностных взаимодействий. Благодаря своим размерам, сопоставимым с размерами клеток, вирусов, белков, ДНК, наночастицы могут приближаться к биообъекту и связываться с ним, вовлекаясь в биохимические процессы в организме.

\section{Л ИТЕРАТ УРА}

1. Campbell W.J., Mertz W. Interaction of insulin and chromium (III) on mitochondrial swelling. American Journal of Physiology-Legacy Content, 1963, 204(6): 1028-1030 (doi: 10.1152/ajplegacy.1963.204.6.1028).

2. Mertz W., Roginski E.E. Chromium metabolism: the glucose tolerance factors. American Journal of Clinical Nutrition, 1971, 33: 163-239.

3. Hasan H.G., Mahmood T.J., Ismael P.A. Studies on the relationship between chromium (III) ion and thyroid peroxidase activity in sera of patients with thyroid dysfunction. Ibn AL-Haitham Journal for Pure and Applied Science, 2017, 24(2): 1-10.

4. Shukla A., Shukla J.P. Hexavalent chromium induced alterations in the nucleic acids and protein metabolism in the liver of the fingerlings of freshwater siluroid, Mystus (M.) vittatus (B1.) Int. J. Pharm. Sci. Res., 2016, 10: 20 (doi: 10.13040/IJPSR.0975-8232.7(6).2667-70).

5. Okada S., Tsukada H., Tezuka M. Effect of chromium (III) on nucleolar RNA synthesis. Biological Trace Element Research, 1989, 21(1): 35-39 (doi: 10.1007/BF02917234).

6. Vincent J.B. Chromium: basic nutritional and toxicological aspects. In: Molecular, genetic, and nutritional aspects of major and trace minerals /J. Collins (ed.). Academic Press, 2016.

7. Vincent J. The nutritional biochemistry of chromium (III). Elsevier, 2018.

8. Sahin K., Sahin N., Onderci M., Gursu F., Cikim G. Optimal dietary concentration of chromium for alleviating the effect of heat stress on growth, carcass qualities, and some serum metabolites of broiler chickens. Biological Trace Element Research, 2002, 89(1): $53-64$ (doi: 10.1385/BTER:89:1:53).

9. Onderci M., Sahin N., Sahin K., Kilic N. Antioxidant properties of chromium and zinc. Biological Trace Element Research, 2003, 92(2): 139-149 (doi: 10.1385/BTER:92:2:139).

10. Kornegay E.T., Wang Z., Wood C.M., Lindemann M.D. Supplemental chromium picolinate influences nitrogen balance, dry matter digestibility, and carcass traits in growing-finishing pigs. Journal of Animal Science, 1997, 75(5): 1319-1323 (doi: 10.2527/1997.7551319x).

11. Florence A.T. The oral absorption of micro-and nanoparticulates: neither exceptional nor unusual. Pharmaceutical Research, 1997, 14(3): 259-266 (doi: 10.1023/A:1012029517394).

12. Desai C., Jain K., Madamwar D. Evaluation of in vitro $\mathrm{Cr}$ (VI) reduction potential in cytosolic extracts of three indigenous Bacillus sp. isolated from $\mathrm{Cr}$ (VI) polluted industrial landfill. Bioresource technology, 2008, 99(14): 6059-6069 (doi: 10.1016/j.biortech.2007.12.046).

13. National Research Council (NRC) Mineral tolerance of animals. Second revised edition, Committee on minerals and toxic substances in diets and water for animals, Board on agriculture and natural resources, Division on earth and life studies. National Academy Press, Washington D.C, 2005.

14. Lien T.F., Yeh H.S., Lu F.Y., Fu C.M. Nanoparticles of chromium picolinate enhance chromium digestibility and absorption. Journal of the Science of Food and Agriculture, 2009, 89(7): 1164-1167 (doi: 10.1002/jsfa.3569).

15. Wang M.Q., Xu Z.R. Effect of chromium nanoparticle on growth performance, carcass characteristics, pork quality and tissue chromium in finishing pigs. Asian-Australasian Journal of Animal Sciences, 2004, 17(8): 1118-1122 (doi: 10.5713/ajas.2004.1118).

16. Wang M.Q., Xu Z.R., Zha L.Y., Lindemann M.D. Effects of chromium nanocomposite supplementation on blood metabolites, endocrine parameters and immune traits in finishing pigs. Animal Feed Science and Technology, 2007, 139(1-2): $69-80$ (doi: 10.1016/j.anifeedsci.2006.12.004).

17. Zha L.Y., Wang M.Q., Xu Z.R., Gu L.Y. Efficacy of chromium(III) supplementation on growth, body composition, serum parameters, and tissue chromium in rats. Biological Trace Element Research, 2007, 119(1): 42-50 (doi: 10.1007/s12011-007-0042-8).

18. Coles E.H. Veterinary clinical pathology. W.B. Saunders Company, Philadelphia, 1986.

19. Boutwell J.H. Clinical chemistry. Laboratory manual and methods. Journal of Medical Education, 1962, 37(2): 158.

20. Батоев Ц.Ж. Фотометрическое определение активности протеолитических ферментов в поджелудочной железе, соке по уменьшению концентрации казеина. В сб.: Труды Бурятского СХИ. Улан-Уде, 1971, вып. 25: 122-126.

21. Газиумарова Л.Д., Титов Л.П., Клюйко Н.Л. Бактериологическая диагностика дисбактериоза кишечника: инструкция по применению. Л.-Минск, 2010. 
22. Оберлис Д., Харланд Б., Скальный А. Биологическая роль макро- и микроэлементов у человека и животных. СПб, 2008.

23. Hussain N., Jaitley V., Florence A.T. Recent advances in the understanding of uptake of microparticulates across the gastrointestinal lymphatics. Advanced Drug Delivery Reviews, 2001, 1(50): 107-142 (doi: 10.1016/S0169-409X(01)00152-1).

24. Sizova E., Yausheva E., Miroshnikov S., Lebedev S., Duskaev G. Element status in rats at intramuscular injection of iron nanoparticles. OSPC - Biosciences, Biotechnology Research Asia, 2015, 12(2): 119-127.

25. Underwood E.J. Chromium. In: Trace elements in human and animal nutrition /E.J. Underwood (ed.). Academic Press, New York, 1997.

26. Oberleas D., Kwun I.S. Confirmation of the mechanism of zinc homeostasis. In: Metal ions in biology and medicine-international symposium, vol. 5 /P. Collery, P. Bratter, V. Negretti de Bratter, L. Khassanova, J.C. Etienne (eds.). John Libbey Eurotext, Paris, 1998: 140-145.

27. Сизова Е.А., Мирошников С.А., Калашников В.В. Цитоморфологические и биохимические показатели у крыс линии Wistar под влиянием молибденсодержащих наночастиц. Сельскохозяйственная биология, 2016, 51(6): 926-936 (doi: 10.15389/agrobiology.2016.6.929rus).

28. Яушева Е.В., Мирошников С.А., Кван О.В. Оценка влияния наночастиц металлов на морфологические показатели периферической крови животных. Вестник Оренбургского государственного университета, 2013, 12(161): 203-207.

29. Bagchi D., Sidney J, Downs B.W., Bagchi M., Preuss H.G. Cytotoxicity and oxidative mechanisms of different forms of chromium. Toxicology, 2002, 180(1): 5-22 (doi: 10.1016/S0300483X(02)00378-5).

30. Sargeant T., Lim T.H., Jenson R.L. Reduced chromium retention in patients with hemochromatosis: a possible basis of hemochromatotic diabetes. Metabolism, 1979, 28(1): $70-79$ (doi: 10.1016/0026-0495(79)90171-9).

31. Ani M., Moshtaghie A.A. The effect of chromium on parameters related to iron metabolism. Biological Trace Element Research, 1992, 32(1-3): 57-64 (doi: 10.1007/BF02784588).

32. Шамсутдинова И.Р., Дерхо М.А. Изменения показателей крови лабораторных животных при введении наночастиц серебра. Известия Оренбургского государственного аграрного университета, 2015, 6(56): 122-124.

33. Speetjens J.K., Collins R.A., Vincent J.B., Woski S.A. The nutritional supplement chromium(III) tris(picolinate) cleaves DNA. Chemical Research in Toxicology, 1999, 12(6): 483-487 (doi: 10.1021/tx9900167).

34. Mooney K.W., Cromwell G.L. Efficacy of chromium picolinate and chromium chloride as potential carcass modifiers in swine. Journal of Animal Science, 1997, 75(10): 2661-2671 (doi: 10.2527/1997.75102661x).

35. Karajanagi S.S., Vertegel A.A., Kane R.S., Dordick J.S. Structure and function of enzymes adsorbed onto single-walled carbon nanotubes. Langmuir, 2004, 20(26): 11594-11599 (doi: 10.1021/la047994h).

36. Vertegel A.A., Siegel R.W., Dordick J.S. Silica nanoparticle size influences the structure and enzymatic activity of adsorbed lysozyme. Langmuir, 2004, 20(16): 6800-6807 (doi: 10.1021/la0497200).

37. Win K.Y., Feng S.S. Effects of particle size and surface coating on cellular uptake of polymeric nanoparticles for oral delivery of anticancer drugs. Biomaterials, 2005, 26(15): 2713-2722 (doi: 10.1016/j.biomaterials.2004.07.050).

\section{1ФГБНУ ФНЦ биологических систем}

и агротехнологий РАН,

460000 Россия, г. Оренбург, ул. 9 Января, 29,

e-mail: 1sv74@list.ru_冈, gavrish.irina.ogu@gmail.com, gubaidullinae@mail.ru;

2ФГБОУ ВО Оренбургский государственный университет,

460018 Россия, г. Оренбург, просп. Победы, 13
Поступила в редакиию

7 ноября 2018 года

Sel’skokhozyaistvennaya biologiya [Agricultural Biology], 2019, V. 54, № 2, pp. 304-315

\title{
DIFFERENT CHROME SOURCES INFLUENCE ON MORPHO- BIOCHEMICAL INDICATORS AND ACTIVITY OF DIGESTIVE ENZYMES IN Wistar RATS
}

\author{
S.V. Lebedev1, 2, I.A. Gavrish1, 2, I.Z. Gubaydullina ${ }^{1}$
}

${ }^{1}$ Federal Research Centre of Biological Systems and Agrotechnologies RAS, 29, ul. 9 Yanvarya, Orenburg, 460000 Russia, e-mail lsv74@list.ru ( $₫$ corresponding author), gavrish.irina.ogu@gmail.com, gubaidullinae@mail.ru;

${ }^{2}$ Orenburg State University, 13, prosp. Pobedy, Orenburg, 460018 Russia 
ORCID:

Lebedev S.V. orcid.org/0000-0001-9485-7010

Gavrish I.A. orcid.org/0000-0002-9377-7673

The authors declare no conflict of interests

Acknowledgements:

Supported financially by the subprogram "Study of the mechanisms of adaptation of the digestive system of mammals and poultry to diets with different ingredient composition of feed" (Decree of the Presidium of the Russian Academy of Sciences No. 132 of 05.07.2017) within the framework of the state task 0761-2018-0031

Received November 7, 2018

doi: 10.15389/agrobiology.2019.2.304eng

\section{Abstract}

Nowadays, issues of mineral nutrition of humans and animals are quite relevant. Highenergy rations, multicomponent feed mixtures and additives in the diets require special attention when optimizing limited microelements. A priori, chromium, being an important trace element in animals, is used to correct carbohydrate, fat and lipid metabolism. Due to its low content in the components of diets, its role in the formation of the microecological status of the body is poorly understood. At the same time, its biological availability in the body depends on the source of chromium. In the present work, using a model object, the Wistar rats, we for the first time compared the

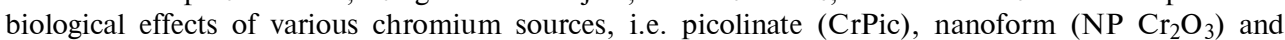
chloride $\left(\mathrm{CrCl}_{3}\right)$ at doses of 300 and $500 \mu \mathrm{g} / \mathrm{kg}$ feed, according to a set of indicators (feed digestibility, hematological parameters, activity of digestive enzymes, composition of intestinal microflora) and established greater bioavailability and more pronounced positive effect of picolinate and chromium nanoparticles on body weight and hematological parameters and ambiguous influence of the studied forms on the activity of digestive enzymes and intestinal microflora. The purpose of this work was to study the biological effect of chromium in various forms and dosages on Wistar rats. The studies were carried out on 105 white male rats weighing 70-80 g under standard vivarium conditions (Federal Scientific Center for Biological Systems and Agrotechnologies of the Russian Academy of Sciences). Animals were divided into seven groups $(n=15$ each). The control group was fed a common diet. The group I diet included $\mathrm{Cr}_{2} \mathrm{O}_{3}$ NPs at a dose of $300 \mu \mathrm{g} / \mathrm{kg}$ feed (NP 300), group II $\mathrm{CrCl}_{3}$ at a dose of $300 \mathrm{mg} / \mathrm{kg}\left(\mathrm{CrCl}_{3} 300\right)$, group III - chromium picolinate (CrPic) at a dose of $300 \mathrm{mg} / \mathrm{kg}$ (CrPic 300), group IV $-\mathrm{Cr}_{2} \mathrm{O}_{3}$ NPs at a dose of $500 \mu \mathrm{g} / \mathrm{kg}$ of feed (NP 500), group V $\mathrm{CrCl}_{3}$ at a dose of $500 \mathrm{mg} / \mathrm{kg}\left(\mathrm{CrCl}_{3} 500\right)$, and group $\mathrm{VI}-\mathrm{CrPic}$ at a dose of $500 \mathrm{mg} / \mathrm{kg}(\mathrm{CrPic}$ $500)$. Nanoparticles were introduced into the feed by mixing. The introduction of chromium in the form of $\mathrm{CrPic}$ and $\mathrm{Cr}_{2} \mathrm{O}_{3}$ NPs at a dose of $500 \mu \mathrm{g} / \mathrm{kg}$, under the same feed consumption, was accompanied by an increase in the body weight of rats by 22.6 and $22.2 \%(\mathrm{p} \leq 0.05)$. The effect of $\mathrm{Cr}_{2} \mathrm{O}_{3}$ NPs expressed as the absence of the reaction of lymphocytes, monocytes and granulocytes, in other cases their level exceeded control values by 14 to $45 \%$. Synthesis of hemoglobin was adequate to stimulation of erythropoiesis, but an increase in the number of platelets resulted in blood sludging, an increase in viscosity and difficulty in perfusion through vessels. This symptom was typical for NP $\mathrm{Cr}_{2} \mathrm{O}_{3} 300, \mathrm{CrCl}_{3} 300$ and $\mathrm{CrCl}_{3} 500$ (the difference with the control is from 70 to $90 \%, \mathrm{p} \leq 0.05$ ). High digestibility of CrPic and NPs $\mathrm{Cr}_{2} \mathrm{O}_{3} 500$ (from 20.2 to $34.0 \%$ ), accompanied by manifestation of hepato- and nephrotoxicity, with signs of oxidative stress, decreased activity of amylase and lipase in the blood plasma, indicating a depressant effect of high doses of chromium on enteropancreatic circulation of the digestive enzymes and metabolic disorders of $\mathrm{Mg}$ and $\mathrm{Fe}$ in the blood. Triglycerides, like true fats, decreased at maximum doses of chromium in the form of chloride and picolinate, confirming their participation in lipid metabolism, causing splitting of excess fat in the body, and reducing the ratio of fat to body weight ratio from 2 (control group) to $0.82\left(\mathrm{NP} \mathrm{Cr}_{2} \mathrm{O}_{3} 500\right.$ ). The indicators of bilirubin and creatinine clearly demonstrate the absence of toxicity at low doses, i.e. $\mathrm{Cr}_{2} \mathrm{O}_{3}$ NPs 300 and CrPic 300. Amylase activity in the pancreas is increased at a dose of $300 \mu \mathrm{g} / \mathrm{kg}$ of $\mathrm{Cr}_{2} \mathrm{O}_{3}$ NPs. Dietary $\mathrm{CrPic}$ in a similar dosage stimulated the activity of lipase and protease, whereas in the 12 duodenal ulcer it led to a decrease in the activity of amylase and lipase. $\mathrm{CrCl}_{3}$ and $\mathrm{CrPic}$ at a dosage of $500 \mu \mathrm{g} / \mathrm{kg}$ reduced the activity of lipase in the duodenum. The specific effect of $\mathrm{Cr}$ NPs $500 \mu \mathrm{g} / \mathrm{kg}$ on the microecological status of the organism was manifested in a decrease in the number of lactic acid bacteria by $55.9 \%$. The number of bifidobacteria was significantly higher, by $48.6 \%$ ( $\mathrm{p} \leq 0.05)$, in the PicCr 500-fed group. The number of enterobacteria in the NP 300 -fed group was $34.8 \%$ lower than the control, while in the other groups their number increased 24.033.7 times $(p \leq 0.05)$. From the totality of the estimated parameters of the intestinal microflora, the use of nanoparticles in the composition of the diet is promising due to the lack of resistance. Thus, chromium of $\mathrm{CrPic} 500$, NP $\mathrm{Cr}_{2} \mathrm{O}_{3} 300$ does not show a toxic effect on the body, and has a stimulating effect on growth, development, digestibility of chromium, the activity of the digestive enzymes and microecological status of the organism, which puts these forms in the category of promising sources of chromium for the correction of metabolism and the microbial composition of the gastrointestinal tract of animals.

Keywords: rats, chromium concentration, productivity, blood biochemical parameters, digestive enzymes, intestinal microflora. 